\title{
Withholding and withdrawing life-sustaining treatment: Experiences in limiting futile therapy from three Polish intensive care departments
}

\author{
Jacek Siewiera ${ }^{1, A-F}$, Dariusz Tomaszewski ${ }^{1,-}$, Jacek Piechocki ${ }^{2, B, E, F}$, Andrzej Kübler ${ }^{3, A, E, F}$ \\ ${ }^{1}$ Department of Anesthesiology and Intensive Therapy, Military Institute of Medicine, Warszawa, Poland \\ ${ }^{2}$ Medical Hyperbaric Center, Warszawa, Poland \\ ${ }^{3} \mathrm{pst}^{\text {st }}$ Department of Anesthesiology and Intensive Care, Wroclaw Medical University, Poland \\ A - research concept and design; $\mathrm{B}$ - collection and/or assembly of data; $\mathrm{C}$ - data analysis and interpretation; \\ $D$ - writing the article; $E$ - critical revision of the article; $F$ - final approval of the article
}

\section{Address for correspondence}

Dariusz Tomaszewsk

E-mail:dtomaszewski@wim.mil.pl

Funding sources

None declared

Conflict of interest

None declared

Received on June 26, 2017

Reviewed on August 19, 2017

Accepted on 0ctober 20, 2017

Published online on October 2, 2018

Cite as

Siewiera J, Tomaszewski D, Piechocki J, Kübler A. Withholding and withdrawing life-sustaining treatment: Experiences in limiting futile therapy from three Polish intensive care departments. Adv Clin Exp Med. 2019;28(4):541-546. doi:10.17219/acem/78775

DOI

10.17219/acem/78775

Copyright

Copyright by Author(s)

This is an article distributed under the terms of the

Creative Commons Attribution Non-Commercial License

(http://creativecommons.org/licenses/by-nc-nd/4.0/)

\section{Abstract}

Background. In intensive care units (ICUs), a patient's vital functions may be maintained, regardless of the patient's chances of survival. A key issue is how to precisely determine the moment in which life-support treatment should be withheld. In many countries, the decision-making process is regulated by the guidelines of scientific societies. However, heuristic errors may influence this process.

Objectives. The objective of this study was to assess factors involved in decisions to implement or withhold treatment in general ICUs in Poland.

Material and methods. The medical records of patients treated in 3 clinical ICUs of general, cardiosurgical and neurosurgical profile were retrospectively analyzed. Patients with a diagnosis of brain death were finally excluded from the study.

Results. The records of 1,449 patients hospitalized between January 1, 2014 and December 31, 2014 were analyzed. Of these, 226 patient cases were evaluated. There were no correlations between the placement of restrictions on resuscitation in specific cases, use of noradrenaline, frequency of blood gas testing, and patients' age. There was a relationship between these factors and the duration of hospitalization in the ICU. There was a direct relation between a "do not resuscitate" (DNR) order in a patient's record and the frequency of both resuscitation procedures and withholding catecholamine treatment in the hours preceding a patient's death.

Conclusions. Treatment was withheld in about 20\% of cases involving dying patients in analyzed ICUS, regardless of age. Placing a limit on treatment consisted of either withholding new procedures or withdrawing existing therapy. The length of stay in the ICU affected the decisions to limit treatment.

Key words: critical care, withholding life-sustaining treatment, withdrawing life-sustaining treatment 


\section{Introduction}

The treatment of patients in the end of life (EOL) period is now an integral component of critical care, with positive results of life-sustaining treatments leading to the widespread implementation of new methods in clinical practice in intensive care units (ICUs). It is now technologically possible to support the functions of individual organs and systems, without having to justify a patient's chances of survival. A key issue facing intensive care physicians is how to precisely determine the moment in which life-support treatment should be withheld.

Many studies have been published to date on this topic, using different methods and materials. These include studies conducted in France, Spain, the US, the UK, Sweden, Norway, and Denmark..$^{1-7}$ One of the largest studies in Europe was based on 127,484 patients admitted to 127 ICUs in England, Wales and Northern Ireland, and concluded that the EOL issues are common in clinical practice. ${ }^{8}$ In many countries, withholding treatment is formally regulated by the guidelines of national scientific societies. ${ }^{5}$ Many of these guidelines recommend noting the decision to withhold treatment in the patient's medical records, sometimes using specially designed "do not resuscitate" (DNR) order forms. ${ }^{5}$

In some cases, the selection of treatment and subsequent escalation of the treatment in the face of imminent death can be out of proportion and unnecessary in view of a patient's clinical status. Heuristic errors in medical judgment regarding the withdrawal or withholding of treatment may stem from subjective decisions by the physician, the physician's experience and underestimation of important factors that can influence the physician's judgment, such as clinical status of the patient, accompanying diseases and prognosis for outcome. ${ }^{9}$ Such errors can also be the result of the physician basing the prognosis on other cases in the literature or clinical practice that bear only a partial similarity to the clinical condition of the patient. ${ }^{9}$ These factors can influence decision-making regarding treatment. ${ }^{10}$

The aim of this study was to assess factors involved in decision-making regarding withholding or withdrawing treatment in Polish ICUs.

For the purpose of this study "withholding" was defined as a situation when therapeutic team refrains from administering new forms of treatment. The term "withdrawing" was used to describe the situation when some medical procedures or drugs were terminated despite having been administrated earlier.

\section{Methods}

After obtaining the approval of the bioethics committee of Wroclaw Medical University (No. KB-470/2013), the medical records of 1,449 patients treated in 3 clinical ICUs of general, cardiosurgical and neurosurgical profile between January 1, 2014 and December 31, 2014 were retrospectively analyzed. A detailed analysis was performed regarding the last $48 \mathrm{~h}$ of treatment for all 226 patients who died in the ICU. There were patients who underwent surgical procedures amongst the analyzed subjects. Patients with a diagnosis of brain death were finally excluded from the study.

The treatments administered in the last $48 \mathrm{~h}$ prior to a patient's death were analyzed. When the treatment period was shorter than $48 \mathrm{~h}$, the first measurement was designated as the first measurement taken at the fixed time for recording the data. Data on the patients' characteristics and existence of DNR orders was recorded. Data on each patient's mean arterial blood pressure (MAP), catecholamine dose, serum concentrations of sodium and potassium, resuscitation, and arterial blood gas (ABG) testing at 6-hour intervals was also recorded. Analysis was performed depending on the time spent in the ICU: (1) more than $48 \mathrm{~h}$, (2) $24 \mathrm{~h}$ or less, and (3) less than $12 \mathrm{~h}$.

\section{Catecholamine treatment}

A noradrenaline, administered intravenously, was most commonly used to maintain perfusion. To evaluate trends, the dose administered was expressed in $\mu \mathrm{g} / \mathrm{kg}$ body weight $/ \mathrm{h}$. The collected data in the analyzed time points was compared as median of catecholamine doses and MAP. The mutual relations between such values gave the possibility to create trends of MAP and catecholamine dose, which were classified as positive, negative, zero, or zero constant. Table 1 shows examples of trends at $48 \mathrm{~h}$. Values of MAP were calculated using the following formula:

$$
\mathrm{MAP}=\mathrm{DP}+1 / 3 *(\mathrm{SP}-\mathrm{DP}),
$$

MAP - mean arterial pressure,

$\mathrm{SP}$ - systolic pressure,

DP - diastolic pressure.

Withholding was defined as no administration of catecholamine, accompanied by a negative trend of MAP value. Withdrawal was defined as a decreasing trend

Table 1. Examples of trends in noradrenaline dosage in 48-hour period of observation

\begin{tabular}{|c|c|c|c|c|c|c|c|c|c|c|c|c|}
\hline \multicolumn{4}{|c|}{ Day 2} & \multicolumn{4}{|c|}{ Day 1} & \multicolumn{4}{|c|}{ Day of death } & \multirow{2}{*}{ Trend } \\
\hline 6 a.m. & 12 p.m. & 6 p.m. & 12 a.m. & 6 a.m. & 12 p.m. & 6 p.m. & 12 a.m. & 6 a.m. & 12 p.m. & 6 p.m. & 12 a.m. & \\
\hline 1.44 & 1.28 & 1.28 & 0.96 & 0.8 & 0.8 & 0.8 & 0.8 & 0.8 & 0.56 & death & death & negative \\
\hline 1.12 & 1.12 & 1.12 & 1.12 & 1.12 & 1.12 & 1.12 & 1.12 & 1.12 & death & death & death & zero \\
\hline 0.32 & 0.32 & 0.32 & 0.32 & 0.8 & 0.64 & 1.92 & 5.6 & 5.76 & death & death & death & positive \\
\hline 0 & 0 & 0 & 0 & 0 & 0 & 0 & 0 & 0 & 0 & death & death & zero constan \\
\hline
\end{tabular}

The doses of noradrenaline are shown in $\mathrm{mg} / \mathrm{h}$. 
in catecholamine doses, accompanied by a falling trend in MAP prior to the death of the patient.

\section{Resuscitation}

A DNR record in a patient's file was taken as a proof of not performing resuscitation (i.e., withholding therapy). The latter was classified as not performing external chest compression and defibrillation after cardiac arrest, as other advanced life support elements remained in place.

\section{Testing frequency of arterial blood gas and electrolyte concentrations}

The frequency of ABG testing provides indirect evidence of the therapeutic effort undertaken by physicians. The frequency of ABG tests in the last 5 days of therapy prior to the patient's death was recorded. When the hospitalization time was shorter than 5 days, the number of tests performed daily was recorded, and relevant trends were identified. The serum concentrations of sodium and potassium ions were recorded for at least $48 \mathrm{~h}$ prior to the death of the patient. Concentrations exceeding normal ranges (135-145 mmol/L for sodium and 3.5 $-5.5 \mathrm{mmol} / \mathrm{L}$ for potassium) were recorded.

\section{Statistical analysis}

Statistical analysis was performed using STATISTICA software package (StatSoft Inc., Tulsa, USA). In the statistical method, because of the nature of the analyzed data, frequency analysis was used. The relationships between the variables were tested using the $X^{2}$ test (Pearson). Regarding the trend analysis, changes in the hemodynamic and laboratory parameters of the patients over time were evaluated. To prevent a subjective assessment of changes in these parameters, the slope of the regression line was used as an indicator of whether a change in a trend was "positive," "negative" or "zero." This method made it possible to develop indicators of changing trends in these parameters.

\section{Sample size calculation}

Because of the insufficient number of published Polish papers in this field, the sample size of the study was not determined.

\section{Results}

In the analyzed period, 1,449 patients were hospitalized in the ICUs. Among them 226 died. Twelve cases were excluded from the study due to the diagnosis of brain death. Finally, the records of 214 patients were analyzed. There were 95 (44.40\%) women and 119 (55.60\%) men. The youngest patient was 19 year old and the oldest was 94 . The characteristics of the analyzed patients regarding
Table 2. Characteristics of the study group

\begin{tabular}{|l|c|c|}
\hline \multicolumn{1}{|c|}{ Diagnosis } & Number of patients & $\%$ \\
\hline CNS damage & 43 & 20.09 \\
\hline Multiple organ failure & 14 & 6.54 \\
\hline Severe sepsis & 93 & 43.46 \\
\hline
\end{tabular}

CNS - central nervous system.

clinical diagnosis are shown in Table 2. One hundred twenty-seven out of 214 (59.35\%) patients were treated surgically, and 87 (40.65\%) patients were not.

In $142 / 214$ cases $(66.35 \%)$, the length of the stay in the ICU did not exceed 7 days. In 14/214 (6.5\%) cases, the hospitalization length exceeded 30 days. Two patients spent 104 and 120 days, respectively, in the ICU. The medical records of 34/214 (15.88\%) patients contained a DNR order in the case of cardiac arrest.

The statistical analysis did not reveal any correlation between the centers where the treatments were administered and the frequency of withholding treatment $(\mathrm{p}=0.784)$. It also revealed no association between the procedures for placing restrictions on resuscitation and the patient's age $(\mathrm{p}=0.2584)$. There was a significant statistical relationship between the presence of a DNR order and the duration of stay in the ICU $(p=0.0000)$. In patients with duration of less than 8 days, a DNR order was present in $10(7.04 \%)$ out of 142 cases. In those with hospitalization durations longer than 30 days, 9 (64.23\%) out of 14 patients had a DNR order. The presence of a DNR order in the medical records showed a statistically significant relationship with the frequency of resuscitation procedures performed prior to the patient's death $(\mathrm{p}=0.00)$. There was also a significant relationship between the presence of a DNR order and withholding noradrenaline treatment in the hours preceding a patient's death $(\mathrm{p}=0.00)$. Detailed data regarding the correlations between withholding treatment and different factors was presented in Tables 3-5.

Table 3. Withholding noradrenaline treatment

\begin{tabular}{|l|c|c|}
\hline \multicolumn{1}{|c|}{$\begin{array}{c}\text { Limits placed on noradrenaline } \\
\text { treatment }\end{array}$} & $\begin{array}{c}\text { Number } \\
\text { of patients }\end{array}$ & $\%$ \\
\hline Withdrawal & 22 & 10.28 \\
\hline Withholding & 31 & 15 \\
\hline Total & 53 & 25 \\
\hline Correlations between limiting noradrenaline treatment & p-value \\
\hline Sex & 0.144 \\
\hline Medical center & 0.784 \\
\hline DNR & 0.0000 \\
\hline CNS damage & 0.0003 \\
\hline $\begin{array}{l}\text { Serum level of sodium above standard (exceeded } \\
145 \text { mmol/L) }\end{array}$ & 0.003 \\
\hline $\begin{array}{l}\text { Serum level of potassium above standard (exceeded } \\
5.5 \text { mmol/L) }\end{array}$ & 0.002 \\
\hline
\end{tabular}

DNR - "do not resuscitate"; CNS - central nervous system. 
Table 4. Association between withholding treatment and the length of ICU stay

\begin{tabular}{|c|c|c|c|c|c|}
\hline \multirow{2}{*}{ Variables } & \multicolumn{5}{|c|}{ Duration of ICU stay } \\
\hline & $<7$ days $(\%)$ & 8-14 days (\%) & $15-30$ days $(\%)$ & $>30$ days $(\%)$ & $p$-value \\
\hline Treatment duration & $142 / 214(66.36)$ & 29/214 (13.55) & 29/214 (13.55) & $14 / 214(6.54)$ & - \\
\hline Limitation of catecholamine treatment & 20/53 (37.74) & $12 / 53(22.64)$ & $12 / 53(22.64)$ & 9/53 (16.98) & 0.0002 \\
\hline DNR order & $10 / 34(29.41)$ & $5 / 34(14.71)$ & $10 / 34(29.41)$ & $9 / 34(26.47)$ & 0.0001 \\
\hline Withholding ABG testing & $18 / 55(32.73)$ & $13 / 55(23.64)$ & $17 / 55(30.91)$ & $7 / 55(12.73)$ & 0.009 \\
\hline
\end{tabular}

ICU - intensive care unit; DNR - "do not resuscitate"; ABG - arterial blood gas.

Table 5. Association between withholding treatment and the patients' age

\begin{tabular}{|l|c|c|c|c|c|}
\hline \multicolumn{1}{c}{ Variables } & \multicolumn{4}{c}{ Age } \\
\cline { 2 - 5 } \multicolumn{1}{c|}{} & $<65$ years (\%) & $66-75$ years (\%) & $76-85$ years (\%) & $>85$ years (\%) & p-value \\
\hline Number of patients & $92 / 214(43.99)$ & $56 / 214(26.17)$ & $46 / 214(21.50)$ & $18 / 214(8.41)$ & - \\
\hline Withholding catecholamine treatment & $20 / 53(37.74)$ & $16 / 53(30.19)$ & $10 / 53(18.87)$ & $7 / 53(13.21)$ \\
\hline DNR order & $12 / 34(35.29)$ & $7 / 34(20.59)$ & $12 / 34(35.29)$ & $3 / 34(8.82)$ \\
\hline Withholding ABG testing & $22 / 55(40.0)$ & $13 / 55(23.64)$ & $14 / 55(25.45)$ & 6.147 \\
\hline
\end{tabular}

DNR - "do not resuscitate"; $A B G$ - arterial blood gas.

In $5 / 214(2.34 \%)$ patients, the time of their hospitalization in the ICU was shorter than $12 \mathrm{~h}$, so in such cases it was impossible to complete the analysis of trends in catecholamine treatment. In 209/214 (97.66\%) cases included in the statistical analysis, the noradrenaline treatment doses were administered from the time of admission to the ICU to at least 2 days before death were recorded. They were recorded during a 12-hour period in 187/214 (87.38\%) patients and in 137/214 (64.01\%) patients during a 24-hour period. The withdrawal of noradrenaline because of a decline in MAP immediately before death was recorded in $22 / 187$ patients who had been in the ICU for at least $24 \mathrm{~h}$ prior to death. The withholding of noradrenaline was recorded in 31/187 cases.

In patients with a 24-hour period of hospitalization before death, the physicians decided to cease catecholamine treatment in 24/214 (11.21\%) cases due to a decline in MAP immediately preceding death, despite the previous use of noradrenaline. Furthermore, in 67/214 cases (31.3\%), 1 day before the patient's death, cardiovascular support was limited to noradrenaline doses smaller than those that had been previously used due to increased hypotension. Central nervous system (CNS) damage was observed in 20/53 (37.73\%) cases when catecholamine treatment had been withdrawn or withheld $24 \mathrm{~h}$ prior to death $(\mathrm{p}=0.0002)$. This relationship between CNS damage and catecholamine limitation remained statistically significant for each available observation time $(\mathrm{p}=0.0026$ for $12 \mathrm{~h}$ and $\mathrm{p}=0.0067$ for $48 \mathrm{~h}$ ). There was no correlation between the patients' ages and the withholding of catecholamine treatment $(\mathrm{p}=0.14)$. There was a clear statistical relationship between the frequency of withholding noradrenaline treatment and the duration of the patient's stay in the ICU ( $p=0.0013)$. Regardless of the length of time in the ICU, this relationship remained unchanged $(p=0.00)$. Among patients who were treated in the ICU for 7 days or less, noradrenaline treatment was withheld in 20/115 (17\%) cases. Noradrenaline treatment was withheld in 9/14 (64\%) cases where the patient remained in the ICU for more than 30 days. Catecholamine treatment was withheld from all $2 / 2(100 \%)$ patients treated for over 90 days. There was no correlation between the treatment center $(p=0.78)$ and sex $(p=0.14)$ of the patient and the withholding of noradrenaline treatment.

Among the patients who remained in the ICU for $24 \mathrm{~h}$ prior to death, the concentration of sodium ions increased in 79/214 (36.91\%) cases. In 45/214 (21.02\%) cases, sodium concentrations surpassed the upper limit of $145 \mathrm{mmol} / \mathrm{L}$. In 113/214 (52.80\%) patients, an increased serum level of potassium was noted. In 46/214 (21.49\%) cases, the serum level of potassium exceeded $5.5 \mathrm{mmol} / \mathrm{L}$.

A decreasing frequency of ABG testing was recorded in 55/214 (25.70\%) patients. Among these patients, noradrenaline treatment was withheld in 23 (10.74\%) cases. There was no correlation between a decrease in the number of ABG tests and the age of the patient who died $(\mathrm{p}=0.6)$. However, there was a relationship between a lower frequency of ABG tests and the length of stay in the ICU $(\mathrm{p}=0.0089)$. A lower frequency of testing was found in half of the cases where hospitalization exceeded 30 days.

\section{Discussion}

More than $50 \%$ of all deaths in the ICU are preceded by some sort of limit placed on treatment. ${ }^{4,11,12}$ A survey of the attitudes of physicians in Poland to withholding treatment showed that these attitudes were reflected in actions taken in ICUs, although documentation on withholding treatment in medical records is very limited. ${ }^{13}$ According to the survey, during the course of their professional careers, 93\% of Polish anesthesiologists admitted not having administered new medications to a patient in the 
EOL stage. Withdrawal was less common but mentioned by $75 \%$ of anesthesiologists. Similar results were obtained in a European study, in which $93 \%$ and $77 \%$ of ICU doctors mentioned withholding and withdrawing treatment, respectively. ${ }^{13}$ In cases of patients who died in the ICU, the prevalence of withholding catecholamine treatment was $24.76 \%$ and the prevalence of withholding renal replacement therapy was $21.49 \% .{ }^{14}$ In the UK, the prevalence of withholding treatment was reported to be $31.8 \%,{ }^{8}$ whereas it was $41 \%$ in Sweden. ${ }^{15}$ In Southern European countries, the reported prevalence of with holding treatment was much lower (20\%). In Northern European countries, different types of limits on treatment were as high as $79 \%$ in Norway and above $80 \%$ in Denmark of all deaths in the ICU. 6,7

The Polish guidelines regarding the ineffective maintenance of organ functions were published in $2014 .{ }^{16}$ The results of the present study indicated that withholding treatment was a common practice in Polish ICUs, although much less common than that observed in Scandinavian ICUs. The prevalence of withholding treatment in Poland was similar to that recorded in others countries, such as Italy, Greece and Portugal. ${ }^{14}$ As indicated by medical records and reported in physician surveys, withholding treatment is less common in these countries than in Northern Europe. ${ }^{14}$ Kübler et al. found that only $10 \%$ of physicians in Polish ICUs admitted to placing DNR orders in patients' medical records. ${ }^{13}$ In contrast, the decision to withhold treatment in Norway was not recorded in only $12 \%$ of cases. ${ }^{6}$ Vincent found that, similarly to Polish physicians, only $8 \%$ of Italian doctors admitted to placing formal DNR orders in a patient's medical records. ${ }^{14}$ This is significantly less than in other analyzed European countries, where $58 \%$ of physicians admitted to placing DNR orders. ${ }^{14}$

Differences in documenting the withdrawal/withholding of treatment may be based on legal and psychological factors. On the one hand, the absence of legal regulations and medical guidelines on mandatory documentation encourages the omission of such documentation in daily medical practice. On the other hand, the psychological burden of making such decisions and the fear of possible moral and legal recriminations may cause physicians to avoid documentation. In Nordic countries, recording the withholding of treatment is a common practice. With the aim of developing a formal procedure, clinicians in France proposed a 4-step, transparent protocol for qualifying and evaluating patients daily which would be based on 4 groups, categorized by the scope of care most appropriate for the clinical condition of the patient. ${ }^{17}$

According to the analysis of Prendergast and Luce, many patients in whom treatment was withheld had already experienced prior CNS damage, and it confirmed that CNS damage had an important impact on a patient's prognosis. ${ }^{18}$ In addition, several reports indicated that older patients gained less therapeutic benefit from critical care than younger patients and that both patients and staff had a low tolerance for aggressive treatments. ${ }^{19-21}$ Some studies reported that advanced age was associated with a higher incidence of withholding treatment. ${ }^{22-25}$ Age was also reported to affect the quality of life. ${ }^{26-28}$ Some reports suggested that the perceptions of treatments for older people by ICU and emergency room physicians differed from their perceptions of treatment indications for younger people. ${ }^{29,30}$ Other studies documented some ethically questionable suggestions to reduce the opportunities for admission to the ICU for patients over $85 .{ }^{31,32}$ The present study found no association ( $\mathrm{p}=0.1384$ ) between withholding catecholamine treatment and age. However, there was a clear correlation between the patient's age and withholding cardiovascular support. There was no link between age and the incidence of DNR orders ( $p=0.292)$ and no link between age and a lower frequency of ABG testing at the EOL stage $(\mathrm{p}=0.3149)$. The frequency of withholding treatment in Poland was not associated with the age of the patient, in contrast to France, the USA and other countries where a smaller range of treatment options may be available for older patients. ${ }^{33}$

This study found a correlation between withholding treatment and the duration of time spent in the ICU. The frequency of withholding cardiovascular support increased with the length of the hospital stay. Treatment was withheld in $16 \%$ of patients who were hospitalized for less than 7 days and in $64 \%$ of patients who were hospitalized for more than 30 days. For hospital stays over 90 days, treatment was withheld in $100 \%$ of cases. A similar relationship was observed regarding the placement of DNR orders. For patients hospitalized for less than 7 days, a DNR order was in place in $7 \%$ of cases. For patients treated for over 30 days, a DNR order was in place in $64 \%$ of cases. The frequency of ABG testing was also related to the duration of the hospital stay. Physicians may perceive the length of stay in the ICU as a prognostic factor when considering making changes to therapeutic targets and indications for treatment.

This study revealed that withholding treatment was more common than withdrawing treatment. In the case of a decline in MAP preceding death, noradrenaline treatment was withheld in 31 (14.5\%) cases, whereas the dose was reduced in $22(10 \%)$ cases, despite a decline in MAP. In Norway, an analysis of data on written protocols governing limiting treatment showed that withholding treatment was almost twice as common as withdrawing treatment. ${ }^{6}$ A similar situation was reported in studies of physicians' conduct in Denmark and Sweden. ${ }^{5}$

\section{Conclusions}

Treatment was withheld in about $20 \%$ of dying patients, regardless of age, in Polish ICUs, suggesting that it is a relatively common practice. Withholding new treatment was much more common than withdrawing treatment. The length of stay in the ICU affected decisions to withdraw or withhold treatment. 


\section{References}

1. Ferrand E, Robert R, Ingrand P, Lemaire F; French LATAREA Group. Withholding and withdrawal of life support in intensive-care units in France: A prospective survey. Lancet. 2001;357(9249):9-14.

2. Esteban A, Gordo F, Solsona JF, et al. Withdrawing and withholding life support in the intensive care unit: A Spanish prospective multicentre observational study. Intensive Care Med. 2001;27(11):1744-1749.

3. Prendergast TJ, Claessens MT, Luce JM. A national survey of endof-life care for critically ill patients. Am J Respir Crit Care Med. 1998;158(4):1163-1167.

4. Smedira NG, Evans BH, Grais LS, et al. Withholding and withdrawal of life support from the critically ill. N Engl J Med. 1990;322(5):309-315.

5. Sjökvist $P$, Sundin PO, Berggren L. Limiting life support. Experiences with a special protocol. Acta Anaesthesio/ Scand. 1998;42:232-237.

6. Hoel H, Skjaker SA, Haagensen R, Stavem K. Decisions to withhold or withdraw life-sustaining treatment in a Norwegian intensive care unit. Acta Anaesthesiol Scand. 2014;58(3):329-336.

7. Jensen HI, Ammentorp J, Ørding H. Withholding or withdrawing therapy in Danish regional ICUs: Frequency, patient characteristics and decision process. Acta Anaesthesiol Scand. 2011;55(3):344-351.

8. Wunsch H, Harrison DA, Harvey S, Rowan K. End-of-life decisions: A cohort study of the withdrawal of all active treatment in intensive care units in the United Kingdom. Intensive Care Med. 2005;31(6): 823-831.

9. Cook DJ. Transdisciplinary research to understand the role of bias and heuristics. In: Curtis JR, Rubenfield GD, eds. Managing Death in the ICU. Oxford, UK: Oxford University Press Inc.; 2001:59-67.

10. Petillä V, Ala-Kokko T, Varpula T, Laurila J, Hovilehto S. On what are our end-of-life decisions based? Acta Anaesthesiol Scand. 2002:46: 947-954.

11. Koch KA, Rodeffer HD, Wears RL. Changing patterns of terminal care management in an intensive care unit. Crit Care Med. 1994;22(2): 233-243.

12. Brieva JL, Cooray P, Rowley M. Withholding and withdrawal of lifesustaining therapies in intensive care: An Australian experience. Crit Care Resusc. 2009;11(4):266-268.

13. Kübler A, Adamik B, Lipińska-Gediga M, Kędziora J, Stróżecki Ł. Endof-life attitudes of intensive care physicians in Poland: Results of a national survey. Intensive Care Med. 2011;37(8):1290-1296.

14. Vincent JL. Forgoing life support in western European intensive care units: The results of an ethical questionnaire. Critical Care Med. 1999;27(8):1626-1633.

15. Nolin T, Andersson R. Withdrawal of medical treatment in the ICU. A cohort study of 318 cases during 1994-2000. Acta Anaesthesiol Scand. 2003;47(5):501-507.

16. Kübler A, Siewiera J, Durek G, Kusza K, Piechota J, Szkulmowski Z. Guidelines regarding the ineffective maintenance of organ functions (futile therapy) in ICU patients incapable of giving informed statement of will. Anaesthesiol Intensive Ther. 2014;46(4):215-220.

17. Holzapfel L, Demingeon G, Piralla B, Biot L, Nallet B. A four-step protocol for limitation of treatment in terminal care. An observational study in 475 intensive care unit patients. Intensive Care Med. 2002; 28(9):1309-1315.
18. Prendergast TJ, Luce JM. Increasing incidence of withholding and withdrawal of life support from the critically ill. Am J Respir Crit Care Med. 1997;155(1):15-20.

19. Boumendil A, Somme D, Garrouste-Orgeas M, Guidet B. Should elderly patients be admitted to the intensive care unit? Intensive Care Med. 2007;33(7):1252-1262.

20. Farfel JM, Franca SA, Sitta Mdo MC, Filho WJ, Carvalho CR. Age, invasive ventilatory support and outcomes in elderly patients admitted to intensive care units. Age Ageing. 2009;38(5):515-520.

21. Nguyen YL, Angus DC, Boumendil A, Guidet B. The challenge of admitting the very elderly to intensive care. Ann Intensive Care. 2011; 1(1):29.

22. Castillo-Lorente E, Rivera-Fernández R, Vázquez-Mata G. Limitation of therapeutic activity in elderly critically ill patients. Critical Care Med. 1997;25(10):1643-1648.

23. Hanson LC, Danis M. Use of life-sustaining care for the elderly. J Am Geriatr Soc. 1991;39(8):772-777.

24. Hamel MB, Phillips RS, Teno JM, et al. Seriously ill hospitalized adults: Do we spend less on older patients? Support Investigators. Study to understand prognoses and preference for outcomes and risk of treatments. J Am Geriatr Soc. 1996;44(9):1043-1048.

25. Boumendil A, Maury E, Reinhard I, Luquel L, Offenstadt G, Guidet B. Prognosis of patients aged 80 years and over admitted in medical intensive care unit. Intensive Care Med. 2004;30(4):647-654.

26. Nicolas F, Le Gall JR, Loirat P, Alperovitch A, Loirat P, Villers D. Influence of patients' age on survival, level of therapy and length of stay in intensive care units. Intensive Care Med. 1987;13(1):9-13.

27. Chelluri L, GrenvikA, Silverman M. Intensive care for critically ill elderly: Mortality, costs, and quality of life. Arch Intern Med. 1995;155(10): 1013-1022.

28. Mahul P, Perrot D, Tempelhoff G, et al. Short and long term prognosis, functional outcome following ICU for elderly. Intensive Care Med. 1991;17(1):7-10.

29. Garrouste-Orgeas M, Timsit JF, Montuclard L, et al. Decision-making process, outcome, and 1-year quality of life of octogenarians referred for intensive care unit admission. Intensive Care Med. 2006;32(7): 1045-1051.

30. Garrouste-Orgeas M, Boumendil A, Pateron D, et al; ICE-CUB Group. Selection of intensive care unit admission criteria for patients aged 80 years and over and compliance of emergency and intensive care unit physicians with the selected criteria: An observational, multicenter, prospective study. Critical Care Med. 2009;37(11):2919-2928.

31. Callahan D. Old age and new policy. JAMA. 1989;261(6):905-906.

32. Callahan D. Controlling the costs of health care for the elderly: Fair means and foul. N Engl J Med. 1996;335(10):744-746.

33. Boumendil A, Aegerter P, Guidet B; CUB-Rea Network. Treatment intensity and outcome of patients aged 80 and older in intensive care units: A multicenter matched-cohort study. J Am Geriatr Soc. 2005;53(1):88-93. 